
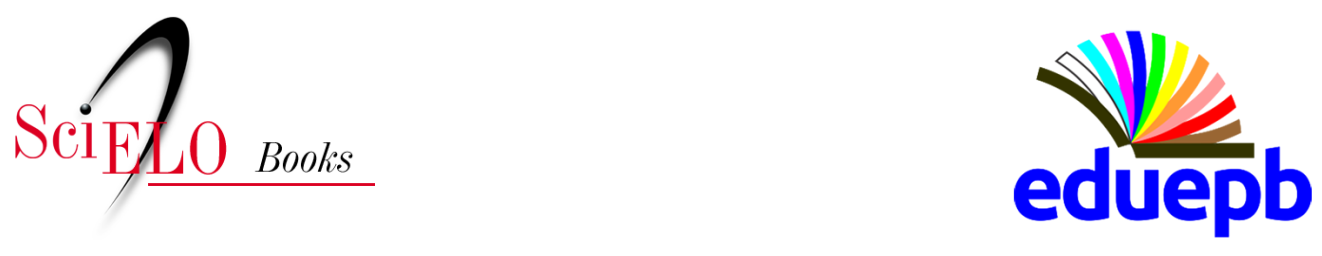

\title{
Introdução \\ Uma agenda para pensar o desenvolvimento regional
}

\author{
Cidoval Morais de Sousa \\ Ivo Marcos Theis \\ José Luciano Albino Barbosa
}

\section{SciELO Books / SciELO Livros / SciELO Libros}

SOUSA, C. M., THEIS, I. M., and BARBOSA, J. L. A. Introdução - Uma agenda para pensar o desenvolvimento regional. In: SOUSA, C. M., THEIS, I. M., and BARBOSA, J. L. A., eds. Celso Furtado: a esperança militante (Desafios): vol. 3 [online]. Campina Grande: EDUEPB, 2020, pp. 21-40. Projeto editorial 100 anos de Celso Furtado collection, vol. 3. ISBN: 978-6586221-12-1. https://doi.org/10.7476/9786586221688.0002.

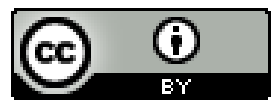

All the contents of this work, except where otherwise noted, is licensed under a Creative Commons Attribution 4.0 International license.

Todo o conteúdo deste trabalho, exceto quando houver ressalva, é publicado sob a licença Creative Commons Atribição 4.0.

Todo el contenido de esta obra, excepto donde se indique lo contrario, está bajo licencia de la licencia Creative Commons Reconocimento 4.0. 


\title{
Introdução
}

\section{Uma agenda para pensar o desenvolvimento regional}

\author{
Cidoval Morais de Sousa \\ Ivo Marcos Theis ${ }^{2}$ \\ José Luciano Albino Barbosa ${ }^{3}$
}

\section{À guisa de apresentação}

O PÓs-Segunda Guerra Mundial o termo DesenVolvimento
passou a ser utilizado para designar um processo de transformação social baseado em dois pilares: industrialização e renda. O desafio de reconstruir a Europa devastada e o avanço da potência militar soviética exigiram do capitalismo formas atualizadas de reprodução. Assim, o que passou a ser conhecido como produção em massa dizia respeito muito mais do que disciplinamento fabril e expansão do consumo. Significou, portanto, a definição de bases sociais, com ênfase nos países centrais, para a retomada de suas economias, sendo os Estados Unidos seu epicentro nervoso. Naquele contexto, desenvolvimento era algo atrelado, do ponto de vista acadêmico, à Economia ou, no máximo, à Sociologia Econômica.

1 Jornalista, doutor em Geociências pela Unicamp, professor e pesquisador da Universidade Estadual da Paraíba (UEPB), vinculado aos Programas de Pós-Graduação em Desenvolvimento Regional e Ensino de Ciências e Educação Matemática. Colabora com o PPGCTS da UFSCar.

2 Economista, $\mathrm{PhD}$ em Geografia Humana pela Eberhard-Karls Universität Tübingen (Alemanha), docente-pesquisador do Programa de Pós-Graduação em Desenvolvimento Regional da Universidade Regional de Blumenau (FURB), líder do Núcleo de Pesquisas em Desenvolvimento Regional, editor da Revista Brasileira de Desenvolvimento Regional e Bolsista de Produtividade em Pesquisa do CNPq.

3 Sociólogo, Doutor em Sociologia pela UFPB, professor efetivo da Universidade Estadual da Paraíba (UEPB), vinculado ao Departamento de Ciências Sociais e docente permanente do Programa de Pós-graduação em Desenvolvimento Regional. 
Ocorre que, no início dos anos de 1970, outras variáveis passaram a compor a cena. A questão ambiental se destacaria como preocupação crescente no debate mundial, muito em decorrência das implicações negativas causadas pelo processo de industrialização (uso de combustíveis fósseis, poluição dos oceanos, escassez da água potável etc.). Nesta linha, cresceria a preocupação, tanto política quanto acadêmica, sobre o desenvolvimento sustentável. O desenvolvimento, como conceito e prática, deslizou da Economia e assumiu a condição de tema transversal a outras áreas, tornando-se, assim, interdisciplinar. Muitos pesquisadores acompanharam tal mudança. Um deles foi Celso Furtado, principalmente quando intensificou sua análise crítica ao processo de subdesenvolvimento, típico do Brasil, que se mostrava desigual, concentrador de riqueza e predador dos recursos naturais.

Em termos contemporâneos, como se mostrará ao longo deste texto e desta coletânea, o desenvolvimento está presente, como temática de estudo, em Universidades do Interior brasileiro, com destaque para o enfoque regional em instituições estaduais, municipais e comunitárias. Pesquisas nas áreas de educação, saúde, cultura, segurança pública, como também investigação sobre Estado e Federalismo, estão na agenda e desafiam os pesquisadores da área. Falar sobre desenvolvimento, hoje, com destaque para a questão regional, remete às dimensões de espaço e poder. Em outras palavras, pensar sobre as escalas e levar em consideração as preocupações geográficas com suas redes e configurações políticas tem sido uma preocupação constante nos trabalhos sobre desenvolvimento regional no país ao longo das últimas décadas.

No caso particular de Furtado, mesmo que ele tenha se tornado mundialmente conhecido como economista, sua produção intelectual é de difícil classificação em termos de área de conhecimento. O seu foco de análise era o Brasil como totalidade, ou seja, as bases históricas e estruturais de sua formação e dinamismo tenso e contraditório. Para usar uma chave de compreensão da Sociologia de Marcel Mauss (2003), em Furtado está presente a ideia do fato social total, no sentido de que a vida social se define por múltiplas esferas (econômica, jurídica, cultural, psicológica etc.). O pensamento regional brasileiro contemporâneo, como veremos adiante, apoia-se em dois pilares que lhe conferem identidade: o estudo do Brasil profundo e a mobilização de diversas áreas do conhecimento, algo inquestionavelmente alinhado com as bases e inspirações furtadianas.. 


\section{A esperança militante}

Uma trilogia... é uma trilogia! E com este terceiro volume de Celso Furtado: a esperança militante finalizamos a tarefa. Lembremos: o primeiro volume reuniu textos que recuperaram a vida pública e a trajetória intelectual deste ilustre paraibano que se tornaria, tanto no campo das ideias quanto no terreno da ação, uma referência para o Brasil e para o mundo - daí se designá-lo "interpretações". Já para o segundo volume foram selecionados textos que correspondem a relatos de/entrevistas com quem conviveu, mais ou menos próximo, com o servidor público exemplar, o ministro comprometido, o professor atento e dedicado, o intelectual competente e, inclusive, o humano tão humano quanto todos/as os/ as seus/suas semelhantes - daí se batizá-lo de "depoimentos". O terceiro volume, finalmente, enfeixa textos que expressam, explícita ou implicitamente, a presença - nalguns casos, a influência e, noutros, até a herança (lições e legado) - do ilustre paraibano em seus respectivos afazeres cotidianos, sobretudo, como docentes e investigadores ligados à academia - daí se nominá-lo "desafios".

Talvez deva ser dito, inicialmente, que um número considerável dos 17 capítulos/textos que (além desta introdução) compõem o presente volume é inédito, enquanto uma parte deles já havia conhecido o mundo na forma de artigo publicado em algum periódico científico. Se se tomar como referência a sua origem, percebe-se uma considerável diversidade regional dos/as 27 autores/as que os assinam (29 no total, se inclusos os autores da introdução): eles/as vêm de quatro macrorregiões, embora, especialmente, do Nordeste e do Sul. Ademais, é notável que muitos dos docentes-pesquisadores que assinam esses capítulos/textos se encontram vinculados a programas de pós-graduação em desenvolvimento regional ou de seu entorno imediato - ponto a ser devidamente considerado mais à frente. E, por fim, outro aspecto que sobressai é a diversidade temática, destacando-se, aqui, a preocupação com aspectos teórico-metodológicoconceituais, com aspectos políticos - o problema das escalas e a questão federativa - e com aspectos educacionais, comunicacionais e culturais.

Se, nesta introdução, se fala de "uma agenda para pensar o desenvolvimento regional”, comecemos, então, por aí. A nossa intuição foi de associar os desafios postos pela obra de Celso Furtado com "desenvolvimento em escala subnacional”. Parece óbvio. Mas, requer uma breve explicação. Em primeiro lugar, como estamos falando do Brasil e desde o Brasil, portanto, de uma sociedade (uma economia, um país, uma formação social...) 
em específico, e partindo do pressuposto de que esta sociedade pode ser caracterizada como "subdesenvolvida", um olhar para a frente, comprometido, não pode ser lançado sobre outras sociedades. Daí concentrarmos a nossa atenção no Brasil e, a partir do legado de Celso Furtado, pensarmos o regional no Brasil.

Aqui cabe um breve parêntesis: mais que por outra razão qualquer, a passagem de Furtado pela CEPAL, certamente, levou-o a referir-se, em diversas ocasiões, à escala do subcontinente (no caso, à América Latina) quando usava o termo "região". Dois exemplos: em A hegemonia dos Estados Unidos e o subdesenvolvimento da América Latina, por exemplo, Furtado escreveu que, "excetuados casos especiais, as economias da região foram seriamente afetadas, ainda que em graus diversos, pelo declínio relativo do comércio internacional de produtos primários" (FURTADO, 1978, p. 79 - itálico nosso). Em Prefácio à nova economia política, ele registrou: "quando um grupo de economistas latino-americanos preparamos, em 1949, o primeiro Estudo Econômico da América Latina, dispúnhamos apenas de dados incompletos das balanças de pagamentos de uns poucos países da região" (FURTADO, 1977, p. 125 - itálico nosso). Está nítido, em ambos os casos, que "região", para o economista paraibano, era a América Latina. Contudo, foram também numerosas as ocasiões em que empregaria o termo "região" para referir-se à escala subnacional.

Um belíssimo exemplo salta do primeiro parágrafo do capítulo XXIII de Formação econômica do Brasil, sua opus magna: "Além da grande corrente migratória de origem europeia para a região cafeeira, o Brasil conheceu no último quartel do século XIX e primeiro decênio deste um outro grande movimento de população: da região nordestina para a amazônica" (FURTADO, 1977, p. 129 - itálicos nossos). Em Perspectivas da economia brasileira, dedicou um capítulo, especialmente, ao "problema das disparidades regionais" (FURTADO, 2012, p. 61-67). Em A fantasia desfeita, começou o prefácio com a lembrança de que, "ao concluir $A$ fantasia organizada, eu assinalara que as crescentes disparidades regionais constituíam sério desafio a quem se preocupasse com o futuro do Brasil e que, como nordestino, isso me preocupava particularmente" (FURTADO, 1989, p. 11 - itálico do autor).

Um último exemplo de que Furtado utilizava, competentemente, o termo região para referir-se à escala subnacional se pode encontrar em O longo amanhecer, aí postulando que, "no caso de uma reformulação constitucional, não seria fora de propósito discutir a possibilidade de 
uma esfera regional de poder" (FURTADO, 1999, p. 55 - itálicos nossos). Em síntese: e não vindo muito a propósito cada questão, cada situação, cada problema específico por ele considerado ao fazer menção ao "regional", interessa reter que, mesmo tendo utilizado "região" para também referir-se à América Latina, é inquestionável que nosso homenageado empregava o termo, e com inegável habilidade, tendo em vista a escala subnacional.

Em segundo lugar, como se está associando os desafios legados pela obra de Celso Furtado ao que vai no território de uma sociedade (uma economia, um país, uma formação social...) em específico - um território, em qualquer caso, diverso em suas características físico-ambientais e socioculturais, e socioeconômica e politicamente heterogêneo e desigual em algum grau -, miram-se, com curiosidade científica, as suas diversas partes constitutivas. Daí justificar-se a composição deste terceiro volume, no qual predominam contribuições de docentes e pesquisadores vinculados a programas de pós-graduação do campo do desenvolvimento regional (alguns, do planejamento urbano e regional). Ou seja, os afazeres profissionais da maior parte, dos/as autores/as que assinam os capítulos que integram o presente volume dizem respeito ao que se passa, precisamente, na escala subnacional.

Aqui também cabe um outro brevíssimo parêntesis: a ocupação intelectual com a escala regional tem já algumas décadas de história. Mas, são as determinações materiais concretas que convidam a pensar - às vezes, induzem mesmo a refletir - sobre uma certa problemática. As conhecidas vicissitudes do desenvolvimento brasileiro, suportavelmente desigual durante o auge do café, se tornaria incomodamente desigual com a industrialização. Localizando-se a atividade manufatureira privilegiadamente em São Paulo, o dinamismo econômico se concentraria no centro-sul do país. A "questão regional" se manifestaria em decorrência da intensificação de fluxos cada vez mais desiguais entre os espaços economicamente mais dinâmicos e a vasta periferia, esta, provedora de matérias-primas e, sobretudo, capital variável.

Celso Furtado não foi apenas o primeiro a perceber a natureza do processo de "atrasamento" do Nordeste, como também o que melhor o entendeu e explicou - e, quando teve a oportunidade, o que melhores recursos mobilizou para frear, quiçá, para inverter os fluxos econômicos que reproduziam "disparidades regionais" em escala ampliada no Brasil. Nos últimos 25 anos, cresceu no país a consciência de que a academia deveria fincar pés e dedicar suas energias no estudo dos problemas econômicos, 
sociais, ambientais e culturais na escala regional. Programas de pós-graduação em desenvolvimento regional, como sinalizamos acima, emergiram não em grandes metrópoles, mas, principalmente, em cidades médias; não na faixa litorânea, mas, sobretudo, no interior; não desde grandes universidades federais estabelecidas, mas, em sua maior parte, desde universidades estaduais e comunitárias. Aí, pois, se identifica, mais ou menos explicitamente, a influência das lições de Celso Furtado no que respeita ao território socioeconômica e politicamente heterogêneo e desigual, às "disparidades regionais" - que convidam a refletir e, às vezes, induzem mesmo a intervir sobre suas causas mais profundas e as possibilidades mais viáveis para o seu necessário enfrentamento.

Em terceiro lugar, por fim, cabe ligar, dialeticamente, o que se passa - inclusive, de uma perspectiva geográfica - em uma sociedade (uma economia, um país, uma formação social...) concreta com os desafios que brotam da obra de Furtado. Se é certo que ele usou com alguma parcimônia uma terminologia mais ao gosto do marxismo, não é menos certo que, quando recorreu a ela, o fez com maestria. Um exemplo - não o único - está no uso dos conceitos de "modo de produção" e "formação social", feito no já referido Prefácio a nova economia política (FURTADO, 1977). A sua evocação aqui tem o sentido de lembrar que o economista paraibano manejava com rara competência o instrumental teórico mais adequado para captar o movimento de uma sociedade subdesenvolvida, periférica e dependente como era - e continua sendo - o Brasil.

No entanto, Celso Furtado não se limitava em, meramente, captar o tal movimento. Sua preocupação fora, desde sempre, com a mudança política da situação que lhe chama atenção. Voltando ao termo região, que nesta coletânea está justificadamente privilegiada, o nosso homenageado não apenas sabia perfeitamente bem o que fazer com este conceito (uma representação do real, que se lhe apresentava como objeto de análise) quando referido à escala subnacional; mas, à luz do caso do Nordeste, também sabia perfeitamente bem que "região" era um termo com o qual podia definir concretamente um lócus de intervenção política. Para que fique mais evidente o que se acaba de indicar, cabe retornar, brevemente, ao prefácio de $A$ fantasia desfeita, quando ali se referiu ao "considerável esforço realizado, com a chamada Operação Nordeste, para mudar o rumo da história na região". Atente-se que, na sequência, ele afirmará que:

Esse esforço se inseria em amplo processo de mudança social, todo ele orientado para recuperar o atraso político e abrir espaço a fim de que parcelas crescentes da população 
regional assumissem na plenitude os direitos de cidadania. Verdadeiras mudanças não poderiam vir senão da renovação dos quadros políticos, com o aumento de sua representatividade e a rejeição, para um desvão da história, das velhas oligarquias (FURTADO, 1989, p. 11).

Note-se que a região é, aqui, desfetichizada. Ou seja, "região" não é uma abstração destituída de gente ou atividade produtiva, mas um espaço concreto de conflito, disputa e luta social. De fato, tornou-se uma categoria analítica central com a qual o economista paraibano captaria o movimento do "atrasamento" do Nordeste em sua plenitude e, simultaneamente, apontaria o/um caminho para romper com os seus condicionantes - políticos! - e instaurar um processo progressivamente emancipatório para o conjunto da população regional. Eis, portanto, o que, dialeticamente, liga uma sociedade concreta como a brasileira com os desafios que emergem de sua rica obra.

\section{As lições do mestre}

Ao longo desta trilogia chamamos Celso Furtado de mestre, seguindo a unanimidade dos intérpretes (volume 1); dos colaboradores e parceiros da Cepal, passando pelo BNDE (hoje BNDES), Sudene, Ministério do Planejamento, exílio e Ministério da Cultura (volume 2); e da nova geração de seguidores, que compõem a maior parte dos autores dos textos aqui publicados (volume 3). A palavra mestre tem duas características que se complementam: ela é substantivo e, ao mesmo tempo, adjetivo. Como substantivo, trata-se de pessoa dotada de excepcional saber, competência, talento em ciência ou arte, artífice, um artesão experiente, e, sobretudo, um indivíduo que ensina. Como adjetivo, quer dizer que é o principal, o gigante, o exemplar, o fundamental, o extraordinário, o inesquecível. Em outras palavras, Celso Furtado.

Não faltaram motivos, no decorrer das nossas carreiras científico-acadêmicas, para chamarmos Furtado de mestre, assim como não faltaram justificativas para os nossos interlocutores nesses três volumes a ele se referirem com essa deferência. Isso significa que, se há mestre, há também lições. Uma coisa é perguntar sobre o legado, e nos parece que muita gente já escreveu a esse respeito, outra é perguntar sobre as lições. O legado sempre se revela numa dimensão mais ampla, com pretensões de totalidade, como uma herança moral, por exemplo. As lições, por sua vez, não excluem essa dimensão, mas trazem o particular, a especificidade, a 
natureza pedagógica, a metodologia do fazer, do proceder, Elas trazem a experiência das trocas dialógicas, a predição e as advertências que sempre acompanham as boas lições.

Olhando para o que vimos e reunimos, particularmente, nos meses em que investimos mais energia neste projeto editorial, chegamos à seguinte conclusão: há muitas lições do mestre que precisam ser revisitadas e/ou compartilhadas, pela luz que lançam à compreensão e ao enfretamento dos tempos sombrios de um presente quase sem futuro. Como legado, é reconhecido que a vida e a obra do economista paraibano foram dedicadas a identificar, refletir e implementar estratégias para superar o subdesenvolvimento brasileiro. Suas contribuições, desde o final dos anos 1940, demonstraram que tanto o técnico quanto o cientista teriam de se debruçar sobre a forma de organização da Administração Pública para compreender a direção e a orientação do Estado como um importante centro de decisão.

Se tomarmos os intérpretes do volume 1 como ponto de partida para evidenciar o legado, a síntese a que chegamos é a seguinte: a obra de Furtado demonstra como a estrutura de produção brasileira e as instituições sociais marcaram a formação de um país regionalmente desigual, em que as elites rurais e urbanas sustentam, pela apropriação do Estado, seus interesses e privilégios. Furtado, ao mesmo tempo em que ofereceu ao Brasil um sistema teórico-metodológico complexo, histórico-estrutural, potente e aberto, atuou concretamente no sentido de orientar suas energias para a construção da nação. Se, para ele, o valor do cientista resulta da mobilização da imaginação e coragem, caberia, também, atuar no plano político, assumindo a responsabilidade de interferir no processo histórico.

A natureza das lições e a sua aplicabilidade são outro detalhe importante nas leituras da vida e obra do mestre. É certo, como bem frisou Szmrecsányi (2001), que a variedade e a importância de suas contribuições, obviamente, não podem ser caracterizadas com fidedignidade num artigo para periódico ou, no nosso caso, nos limites de um capítulo de livro. Destacamos, aqui, apenas aquelas que se repetiram, com mais intensidade, nas vozes e nos textos dos interlocutores que mobilizamos nos três volumes. E elas são de três naturezas: epistemológicas, técnicas e políticas.

Do ponto de vista epistemológico, Furtado: a) explicitou uma compreensão de ciência, com forte peso moral, considerando-a "a forma de conhecimento que, por excelência, capacita o homem para antecipar os 
acontecimentos, subordinar o mundo físico a seus propósitos e submeter outros homens ao seu domínio" (FURTADO, 2013: 484); b) dedicou atenção especial a conceitos que possibilitaram uma interpretação inovadora da formação socioeconômica do Brasil e da América Latina, como o de subdesenvolvimento; c) introduziu - para alguns, "fundou" -, no Brasil e na América Latina, os estudos sobre desenvolvimento regional; e d) construiu as suas contribuições analíticas e teóricas, adotando e defendendo o enfoque interdisciplinar, dedicando, de modo particular, uma de suas obras ao tema - Pequena introdução ao desenvolvimento: enfoque interdisciplinar (1980).

Celso Furtado tornou-se economista, assumindo que procurava exercer a profissão com o auxílio de outras disciplinas. Entre elas, era a história aquela que, desde cedo, lhe propiciou a visão ampla de que reiteradamente fala em seus textos. Embora economista de grande competência, com o domínio da teoria e do instrumental matemático, considerava que a realidade que queria entender - e explicar - não se prestava a uma tradução fidedigna se não amparada em uma episteme generosa, fundada em múltiplos saberes dialeticamente integrados e interligados. A partir daí é que se dedicou a estudar o fenômeno do desenvolvimento, a desvelar a sua contraparte na periferia, o subdesenvolvimento, e a oferecer um entendimento do Brasil contemporâneo. Não obstante seja Formação Econômica do Brasil uma obra de maturidade, publicada quando tinha menos de 40 anos, Celso Furtado foi aperfeiçoando a sua compreensão do Brasil (e da América Latina) ao longo dos anos em que exerceu cargos públicos e pode dedicar-se à academia.

Do ponto de vista técnico, Furtado também foi exemplar, como atesta o detalhado estudo de Tenório e Wanderley (2018): começou como um dos membros da "elite técnica", que tomou conta dos novos órgãos da administração pública, no DASP (Departamento Administrativo do Serviço Público), no início dos anos 1940, assumiu uma diretoria no BNDE, e chegou à gestão no primeiro escalão do governo federal em pelo menos três postos chaves: Superintendência da Sudene (1959), Ministro Extraordinário do Planejamento (1962) e Ministro da Cultura (1986). Destaca-se, desta dimensão, um Furtado que, desde cedo, se interessou por organização e planejamento, formação de administradores públicos, estudo pormenorizado das repartições e pelo entendimento das diferentes composições que as organizações poderiam assumir. É sobre esses temas que realiza seus primeiros trabalhos técnicos, enfatizando a necessidade de um novo perfil para o gestor público. 
Quanto a dimensão política há características na atuação de Furtado que são em si mesmas uma crítica virulenta à moderna tradição brasileira. Nascido em meio a realidades de mando, coronéis e cangaceiros, o economista de Pombal parece ter feito escola no enfrentamento dessas estruturas. Ao mandonismo, respondeu com democracia; à captura do Estado pelas elites agrárias, respondeu com republicanismo; às tentativas de barganha por maiores fatias do bolo a ser repartido pelo Estado, negociou firmemente em bases morais e éticas, "sem trair o principal", como diria Bacelar (2020); aos interesses mesquinhos e particularizados de governos, respondeu com políticas integradas de desenvolvimento, fortalecendo uma nova relação entre entes federados numa mesma região.

\section{A agenda da coletânea}

As contribuições enviadas para este volume foram, em grande medida, estimuladas por convites a investigadores que estavam, de alguma forma, vinculados a estudos, pesquisas, atividades de extensão e produções tecnocientíficas do campo do desenvolvimento regional. Foram mais de três meses de provocações, diálogos e coletas. Os textos recebidos e selecionados foram editados com a participação direta de seus respectivos autores. Entre leituras, devoluções dialógicas e ajustes, o resultado, já comentado acima, expressa, em nosso ver, o espírito da trilogia: a esperança militante. Tentamos, para efeito didático, e seguindo os volumes anteriores, fazer um arranjo temático: os conteúdos foram dispostos em quatro grandes blocos: Dilemas epistemológico-conceituais; Escalas, Políticas, Territórios; Federalismo; e Comunicação, Educação e Cultura. A seguir, uma pequena síntese crítica dos 17 textos que integram esta coletânea, como um convite à leitura e discussão.

$\mathrm{O}$ texto que abre o primeiro bloco - $O$ que é desenvolvimento regional? Uma aproximação a partir da realidade brasileira - do professor Ivo Marcos Theis, agenda pelo menos três grandes desafios: a) oferecer uma compreensão "um pouco mais contextualizada" do que é desenvolvimento regional, com uma boa leitura do panorama internacional; b) problematizar impactos e influência da obra de Celso Furtado nos estudos recentes sobre a problemática regional, tomando como referência empírica a produção intelectual que vem tendo lugar na universidade brasileira, em especial, nos programas de pós-graduação em desenvolvimento regional, mas também nos grupos de pesquisa e na atuação dos próprios pesquisadores, reservando uma atenção especial, também, para 
uma leitura crítica dos periódicos reconhecidos pela área; e c) fazer avançar uma formulação mais utópica de desenvolvimento regional a partir de uma aproximação da realidade sociocultural brasileira, que leve em consideração o seu passado colonial, o sofrimento dos povos originários e das populações compulsoriamente transplantadas, a presença das mulheres e a diversidade da natureza.

A proposição de Marcos Antônio Mattedi, no texto Subsídios para um programa forte em desenvolvimento regional, é que o desenvolvimento regional não constitui mais apenas o ponto de chegada que se alcança seguindo os caminhos traçados pela economia, pela geografia, pela sociologia, pela antropologia, pela ciência política, mas, também, o ponto de partida por meio do qual é possível compreender essa realidade de uma nova forma. Mattedi faz uma breve revisão das estratégias epistemológicas de concepções que podem ser adotadas para interpretar a cientificidade das relações entre desenvolvimento e região; analisa teorias do desenvolvimento regional para estabelecer um modelo conceitual que permita superar o que chama de abordagens bidimensionais; concentra-se na reformulação do conceito de desenvolvimento regional a partir dos subsídios extraídos do cálculo da indicação, desenvolvido a partir das contribuições de George Spencer-Brown; e fecha o capítulo apresentando princípios e bases epistemológicas para orientar a pesquisa e o pensamento com desenvolvimento regional.

Para Jandir Ferreira de Lima, em $O$ desenvolvimento regional como fenômeno regional, apesar de as teorias da localização terem introduzido os elementos distância, espaço e lugar no debate sobre a organização do espaço, eles não foram suficientes para explicar as desigualdades regionais. Segundo Lima, essas teorias têm como restrição os aspectos sistêmicos, complexos e relacionais do desenvolvimento socioeconômico. De forma ampla, a teoria do desenvolvimento regional busca, na visão de Lima, conhecer o papel do espaço, da política pública e dos territórios na melhoria da qualidade de vida e no progresso econômico das regiões. Por isso, interage com conceitos como centralidade, redes de informação, atração, repulsão, distância, ambiente de inovação, dentre outros, numa gama ampla de relações. Na leitura do autor, uma agenda de pesquisa nesse campo deveria se voltar, também, à dinâmica do subdesenvolvimento regional - um tema ainda esquecido pelos estudos regionais.

Na agenda da professora Virginia Elisabeta Etges, em $A$ dimensão regional do desenvolvimento: contribuições teóricas e experiências sul-americanas, a primeira década do século XXI foi marcada por importantes 
avanços na discussão sobre os processos territoriais de desenvolvimento. É nesse contexto que, segundo ela, a região, enquanto particularidade territorializada do processo geral de acumulação capitalista, adquiriu um novo sentido: ao mesmo tempo em que expressa formações socioeconômicas, ou sócio-espaciais, expressa, também, o contra-movimento à globalização. Na América do Sul, conforme a autora, vivemos, na atualidade, um forte movimento de resgate do sentido do desenvolvimento regional, ao mesmo tempo em que os interesses hegemônicos deixam suas marcas no território, através de organizações como a Iniciativa de Integração Regional Sul Americana (IIRSA). Entretanto, com o fortalecimento das regiões através de sua organização, como é o caso dos Conselhos Regionais de Desenvolvimento e dos Consórcios Intermunicipais, no sul do Brasil, a tensão entre as forças globalizantes e as forças regionalizantes vem se acentuando, evidenciando um marcante movimento sócio-territorial. Em outras palavras, se a ordem global busca impor, a todos os lugares, uma única racionalidade, as regiões, por sua vez, respondem ao mundo segundo diversos modos de sua própria racionalidade.

O ensaio Política Nacional de Desenvolvimento Regional no Brasil: incapacidade ou não-acontecimento?, de Rainer Randolph, começa com uma assertiva furtadiana: não é tarefa fácil captar a natureza do subdesenvolvimento. São muitas as dimensões e, nem sempre, as que estão visíveis são as mais significativas. A proposta do autor é identificar "a natureza daqueles que são responsáveis pelo desenvolvimento (e, por tabela, o não-desenvolvimento)". Para isso realiza quatro movimentos: a) indica a política de desenvolvimento regional em nível federal como assunto da investigação; b) empreende um grande esforço analítico para mostrar as limitações de se julgar o sucesso ou fracasso dessa política, partindo apenas de seus (aparentes) resultados; c) problematiza a dimensão dialética entre estrutura institucional e dinâmicas de atuação, no contexto da execução da políticas e d) tensiona que não há como adiantar respostas definitivas se as "falhas" da política têm a sua origem em certas incompetências ou apontam para sua compreensão como "não-acontecimento", na medida em que uma boa parte dos especialistas questiona até se devem ser consideradas ou não como políticas de desenvolvimento regional.

Em Escalas espaciais, território e desenvolvimento regional: notas para discussão teórica e metodológica, Rogério Leandro Lima da Silveira, enfatiza que escalas espaciais estão presentes em nossa vida, em nossas representações da realidade, em nossas ações, relações, lutas sociais. 
Também estão presentes nos processos sociais e econômicos e na construção e implementação das políticas públicas de planejamento e desenvolvimento regional. O ensaio, nesse contexto, recobra a importância das escalas espaciais ou geográficas na análise do território e dos processos de desenvolvimento e planejamento regional: apresenta o conceito de escala espacial e a necessária distinção com o conceito de escala cartográfica; reflete sobre a especificidade e a relação entre escala dos fenômenos, escala de análise e escala de ação; aborda a ideia-chave que fundamenta a compreensão de escalas como constructos sociais; ou seja, elas são produzidas, socialmente, por agentes concretos, em suas relações e estratégias políticas nos territórios; e, por fim, discute a relação entre a escala espacial e a dinâmica territorial, com a intenção de contribuir teórica e metodologicamente para a compreensão, análise dos processos e políticas de desenvolvimento regional.

O capítulo Para pensar as espacialidades e as temporalidades dos processos sociais regionalizados em conjuntura de crise disruptiva, de Carlos Antônio Brandão, agenda a necessidade de a área de desenvolvimento regional avançar em uma teorização do papel fundante das decisões cruciais dos agentes dominantes e seus contrapoderes, defendendo a realização de atividades de ensino, pesquisa e extensão que não negligenciem as estruturas constitutivas mais gerais e, ao mesmo tempo, não percam as lógicas das conjunturas mais particulares. A questão regional, no seu entendimento, deveria se expressar, antes de tudo, na forma de decisões ousadas, nucleadas na provisão de direitos e bens e serviços coletivos. As pesquisas e os cursos de pós-graduação em desenvolvimento regional deveriam continuar a mergulhar nas suas especificidades geográficas, históricas, estruturais e conjunturais dos seus respectivos mundos micro e mesorregionais, buscando captar toda a riqueza da diversidade e da complexidade de seus contextos e posicionalidades frente ao todo. Não deveriam, no entanto, flertar com concepções teórico-metodológicas conservadoras, que já demonstraram estar dissociadas de nossas formações e realidades socioeconômicas, territoriais, culturais e espaciais.

Para os autores de Processos de apropriação espacial: contribuições para estudos futuros, Thiago José Arruda de Oliveira e Waldecy Rodrigues, se a humanidade só conseguiu gerar riquezas apropriando-se de espaços ao redor do mundo, por que ainda persistem problemas elementares como as desigualdades de renda? Partindo dessa provocação, problematizam, historicamente, a relação entre espaço e sociedade e pontuam que, apesar de os Homo sapiens existirem a milênios, 'pouco se conhece 
sobre a nossa função no mundo'. Colocar essa evidência em forma de variável, segundo Oliveira e Rodrigues, é o principal desafio dos estudiosos da área de desenvolvimento regional. Para isso torna-se necessário que os próximos estudos elevem a variável felicidade humana a um nível de importância similar à da renda, patrimônio e serviços. Em relação à sua aplicabilidade no Brasil, em vista da infiltração do agronegócio na zona rural, do avanço das igrejas pentecostais e neopentecostais na sociedade e do tráfico de drogas nas cidades, esse tipo de análise possui um vasto campo de possibilidades. O principal desafio, com o já sinalizado, será inseri-lo, especialmente, nos estudos que tratam sobre desenvolvimento.

A proposição defendida, em Aproximações teóricas-conceituais entre ordenamento do território e desenvolvimento regional, por Lívia Gabriela Damião de Lima e Larissa da Silva Ferreira Alves (UERN), é que, considerando que o ordenamento do território (OT) é uma ferramenta fundamental a ser utilizada pelo Estado, no que diz respeito a organização espacial do território, o desenvolvimento regional (DR) não pode ser negligenciado. $\mathrm{O}$ Estado é enfatizado como um agente regulador, modificador e produtor do território. $\mathrm{O}$ trabalho se articula em dois movimentos: o primeiro aborda a concepção do ordenamento territorial, enquanto elemento fundamental na organização espacial do território, tendo o Estado como principal ator; e, no segundo, problematiza o conceito de desenvolvimento regional como elemento necessário no processo de ordenação do território, considerando a importância da efetivação de políticas descentralizadoras para o desenvolvimento.

A proposta do texto Diferenciais produtivos no Semiárido brasileiro: o caso do Ceará, de Maria Daniele Cruz dos Santos e Francisco do O' de Lima Júnior é analisar a estrutura produtiva assentada no Semiárido cearense nos anos 2000. Conforme os autores, ao longo da formação do território, os fenômenos percebidos na economia e no sistema urbano que acompanharam a tendência da urbanização foram: a) a modernização, dinamização e inserção de atividades produtivas; b) as políticas institucionais do Estado voltadas para o desenvolvimento do tripé indústria-lazer/turismo-agronegócios; c) o avanço econômico e populacional da Região Metropolitana de Fortaleza (RMF); d) alguns centros médios urbanos que polarizam o interior do estado; e) expansão das fronteiras da especulação imobiliária em todo o território do estado e; f) o processo de metropolização. Para Santos e Lima Júnior essas alterações casam, significativamente, com as mutações temporais ocorridas na 
estrutura produtiva cearense, mais especificamente no litoral e nos polos de desenvolvimento, objeto do estudo em questão.

Em O desenvolvimento regional em Celso Furtado: a coordenação federativa e as implicações institucionais, os autores Luciléia Aparecida Colombo, Thales Haddad Novaes de Andrade e Aristides Monteiro Neto tomam como pano de fundo as assimetrias federativas para defenderem que a Sudene representava uma arena de resolução de conflitos federativos, estabelecendo pontes entre o governo federal e os governos estaduais e, destes, entre si. Segundo eles, foi uma política institucional que priorizou experiências cooperativas, apesar da grande oposição formada em torno tanto da aprovação da lei que a instituiu formalmente, como da aprovação de seus planos diretores. Na assertiva dos autores, repensar a postura de Celso Furtado não apenas como um grande intelectual, mas, sobretudo, como um militante do planejamento regional é essencial, também nos turbulentos dias atuais. A atualidade de sua obra é, de fato, um respiro em meio à indefinição recorrente de planos de desenvolvimento regional que requerem a cooperação e a interlocução constante entre os entes federados para a obtenção de efetividade.

Os autores de Federalismo Brasileiro: uma revisitação das contribuições de Celso Furtado, Rosangela dos Santos Alves Pequeno e Fernando Cézar de Macedo, agendam uma leitura importante das contribuições de Celso Furtado sobre o federalismo brasileiro. Destacam, nesse contexto, duas questões: a concepção de federalismo de Furtado e a relevância da questão regional para o federalismo, como fator dinâmico no processo de desenvolvimento nacional. Os autores lembram que a compreensão de Furtado partiu do seu interesse por entender as transformações da economia brasileira. Entretanto, diante das desigualdades sociais e econômicas existentes entre as regiões brasileiras, a saída vista pelo economista paraibano era buscar, por meio de mecanismos cooperativos, uma melhor distribuição das atividades econômicas no país e um maior equilíbrio político entre os participantes da federação. Sob este prisma, a visão macroespacial na articulação e condução do processo de desenvolvimento da nação é contraposta à abordagem da atuação dos consórcios públicos, que potencializam ações de articulação microrregional na estrutura federativa brasileira atual.

A proposta do artigo Aproximações entre estudos culturais e desenvolvimento regional: uma proposta teórico-metodológica para estudar a comunicação na interdisciplinaridade, de Ângela Cristina Trevisan Felippi e Grazielle Betina Brandtx é de inserir a perspectiva comunicacional no 
campo do desenvolvimento regional, a partir de um viés orientado para a sua dimensão cultural. Observam que a cultura pode ser pensada enquanto produção e prática social, expressas por meio de representações simbólicas que impregnam o espaço geográfico. O texto concentra-se na importância dos lugares e dos territórios, reportando aos significados que o espaço adquire a partir da experiência pessoal de seus indivíduos. A atenção à dimensão cultural, por esse enfoque, agenda formas de valorizar a comunicação e incentivar o debate interdisciplinar no campo do desenvolvimento regional.

Para Monica Franchi Carniello e Moacir José dos Santos, autores do texto Comunicação e Desenvolvimento Regional, a reflexão sobre essa relação pode ser sistematizada em três abordagens: a difusionista, a participativa e a do bem-estar social. A mera presença de um sistema de mídia em uma região não garante seu uso aplicado ao desenvolvimento regional. Os fluxos de comunicação não se realizam de modo abstrato, pois estão vinculados aos processos sociais que os definem. A comunicação é uma variável fundamental para se investigar se o desenvolvimento em uma conjuntura regional ou nacional supera o espectro econômico e abrange aspectos relacionados às demais variáveis que caracterizam o desenvolvimento global. Assim, o desafio de investigar o desenvolvimento, segundo os autores, é situá-lo de modo permanente na conjuntura da dinâmica capitalista para se entender as características de sua consecução em um determinado momento histórico e espacialidade.

Considerando a diversidade temática da agenda de desafios que estamos tentando articular nesta coletânea, o artigo A educação como fator de desenvolvimento regional, de Flávio Eliziario de Sousa e Mariane Freiesleben, chama atenção para quatro questões importantes da relação Educação-Desenvolvimento: a) o papel do Estado na articulação, implementação e regulamentação das políticas públicas de desenvolvimento regional; b) uma compreensão inovadora de desenvolvimento que não opera sem a intervenção do Estado; c) o lugar e papel da educação como fator de desenvolvimento regional, no empoderamento de indivíduos e territórios; d) o papel dos Institutos Federais (e, de modo mais amplo, das IES Públicas) na articulação e construção de soluções coletivas e sustentáveis para o enfrentamento dos desafios críticos ao desenvolvimento das regiões mais vulneráveis. $\mathrm{O}$ conjunto de suas atividades, segundo os autores, passa a dar origem a uma força de atração de consumidores e empresas, contribuindo para gerar um crescimento econômico-social local/regional. 
No texto Um olhar teórico-metodológico sobre processos de intervenção e de extensão para o desenvolvimento regional, a proposta de Cidonea Machado Deponti é apresentar e discutir questões relacionadas aos processos de intervenção e de extensão em contextos de desenvolvimento regional. Para a autora, desenvolvimento é um processo de mudança social, complexo, multi-ator, multi-escalar, multidimensional, carregado de heterogeneidades de práticas, de processos e de políticas, sem limites definidos no tempo e no espaço, que avança e retrocede. Nos processos de intervenção, o termo mediação ganha foça e é constituído por múltiplos processos de negociação entre as partes envolvidas, nem de cima para baixo (top-down), nem de baixo para cima (buttom-up), mas de encontro, de interface, em que os diferentes conhecimentos se entrelaçam, tornando-se um híbrido, que valoriza tanto o conhecimento técnico quanto o saber-fazer. A mediação leva ao sentimento de pertencimento ao fazer parte do processo.

A agenda do texto Celso Furtado, o (Sub) Desenvolvimento numa perspectiva cultural e a criatividade nos Maracatus Nação de Pernambuco, de Tiago Macêdo Bezerra Maia e João Morais de Sousa se articula em três eixos propositivos: oferecer uma melhor compreensão da dimensão cultural dos processos e problemas do (sub)desenvolvimento, na América Latina e, sobretudo, no Brasil; evidenciar o papel da criatividade que, como força motriz, constitui a cultura, ao mesmo tempo em que é por ela é constituída no enfrentamento das questões que surgem diariamente na sociedade; e desvelar a criatividade e resistência da cultura popular e da religiosidade dos negros presentes nos Maracatus Nação de Pernambuco, à luz da perspectiva cultural furtadiana. Assim, o capítulo apresenta um panorama do diálogo de Furtado com a antropologia e, a partir deste, alguns dos aspectos mais relevantes das contribuições de suas reflexões culturais que marcam a atualidade e a urgência do resgate de seu pensamento.

\section{Papel dos intelectuais}

Em linhas gerais, a síntese acima procurou dar pistas aos leitores das preocupações, inquietações, agendas e desafios que marcam o conjunto dos textos selecionados para este volume. Retomando o que já dissemos, e partindo das contribuições dos capítulos que se sucedem ao longo das próximas páginas, podemos afirmar que o pensamento regional brasileiro se apresenta, hoje, com pelo menos cinco características importantes: a) 
o estudo do Brasil profundo, um traço importante que vem da obra de Furtado; b) uma agenda temática diversa em que o olhar para o território ganha ênfase como um importante ponto de partida; c) uma compreensão de desenvolvimento que se constrói nas contradições do mainstream e que também ganha corpo, não apenas como resultado de políticas de Estado ou Governos, mas como campo científico a partir do qual se propõe intervenções transformadoras (no fazer científico e na sociedade); d) a entrada em cena de novos atores e formações e a proeminência da interdisciplinaridade como horizonte do pensar e agir; e e) a configuração de uma tendência (também inspirada em Furtado) de não apenas apontar o problema ou fazer diagnósticos, mas de construir, de forma criativa, inclusiva e pertencida, as possibilidades de solução.

Não temos dúvidas de que o centenário de nascimento do mestre Furtado foi uma oportunidade, ímpar, para leituras e releituras de sua vasta obra, num contexto singular de crises, no qual a pandemia do Coronavírus é uma das expressões de esgotamento do atual modelo de desenvolvimento. O Brasil, como bem acentua Brandão, (2020), necessita construir estratégias e instituições capazes de conectar os canais de interação entre crescimento econômico, integração territorial, construção de cidadania social, ciência, tecnologia e inovação e aprimoramento de capacidades humanas emancipadoras. Entretanto, como Furtado (2002) mesmo lembrava, desarmar essa armadilha "não é tarefa simples". Segundo ele, somente a criatividade política impulsada pela vontade coletiva poderia superar esse impasse. Mas essa vontade, no seu entendimento, requeria um reencontro das lideranças políticas com os valores permanentes de nossa cultura e uma participação maior do povo no sistema de decisões. Sem isso, o desenvolvimento nem se alimentaria da autêntica criatividade de nosso povo, nem contribuiria para a satisfação dos anseios legítimos da nação. Eis, portanto, o grande desafio.

Por falar em desafio, Furtado cuidou de refletir sobre o que definia para si como "desafios". Pinçamos, aqui, o que parece ser suficientemente representativo do que, por um lado, deve ter animado os/as autores/as dos capítulos/textos que integram esta coletânea e, por outro, pode servir de inspiração - um convite! - para a sua leitura por parte de quem talvez já tenha tido sua curiosidade devidamente despertada. Em O capitalismo global, escreveu:

O desafio que se coloca no umbral do século XXI é nada menos do que mudar o curso da civilização, deslocar o seu eixo da lógica dos meios a serviço da acumulação num curto 
horizonte de tempo para uma lógica dos fins em função do bem-estar social, do exercício da liberdade e da cooperação entre os povos" (FURTADO, 1998, p. 64 - itálico nosso).

Que responsabilidade a daqueles/as que ousam compartilhar de tal pensamento, que assumem pretender cultivar alguma parte de suas lições e de seu rico legado! Arriscamos, todavia, o palpite de que o desafio do mestre está subjacente aos - sim, talvez imbricado com os - desafios que caracterizam as contribuições contidas neste terceiro volume em sua homenagem. Parece-nos, entretanto, que, ao final desta árdua, prazerosa e gratificante tarefa de articulação, organização e edição da trilogia, o que nos desafia com maior intensidade é assumirmos o grande papel que o mestre preconizava para os "trabalhadores intelectuais":

Cabe a estes aprofundar a percepção da realidade social para evitar que se alastrem as manchas de irracionalidade que alimentam o aventureirismo político: cabe-lhes projetar luz sobre os desvãos da história, onde se ocultam os crimes cometidos pelos que abusam do poder; cabe-lhes auscultar e traduzir as ansiedades e aspirações das forças sociais ainda sem meios próprios de expressão" (FURTAD̉O, 2002, p. 37).

Boa leitura!

\section{Referências}

ARAÚJO, Tania Bacelar. Celso Furtado: um intelectual com o pé no chão. In. SOUSA, Cidoval Morais; THEIS, Ivo Marcos; BARBOSA, José Luciano Albino. Celso Furtado: a esperança militante (vol 2). Campina Grande: EDUEPB/A UNIÃO, 2020. p. 247-269.

BRANDÃO, Carlos Antonio. Para pensar as espacialidades e as temporalidades dos processos sociais regionalizados em conjuntura de crise disruptiva. In. SOUSA, Cidoval Morais; THEIS, Ivo Marcos; BARBOSA, José Luciano Albino. Celso Furtado: a esperança militante (vol 3). Campina Grande: EDUEPB/A UNIÃO, 2020.

FURTADO, Celso. Formação econômica do Brasil. 15 ed. São Paulo: Nacional, [1959] 1977.

FURTADO, Celso. Prefácio a nova economia política. 2 ed. Rio de Janeiro: Paz e Terra, 1977. 
FURTADO, Celso. A hegemonia dos Estados Unidos e o subdesenvolvimento da América Latina. 3 ed. Rio de Janeiro: Civilização Brasileira, 1978.

FURTADO, Celso. A fantasia desfeita. Rio de Janeiro: Paz e Terra, 1989.

FURTADO, Celso. O capitalismo global. 2 ed. São Paulo; Rio de Janeiro: Paz e Terra, 1998.

FURTADO, Celso. Em busca de novo modelo: reflexões sobre a crise contemporânea. São Paulo: Paz e Terra, 2002.

FURTADO, Celso. O longo amanhecer: reflexões sobre a formação do Brasil. Rio de Janeiro: Paz e Terra, 1999.

FURTADO, Celso. Em busca de novo modelo: reflexões sobre a crise contemporânea. 2 ed. São Paulo; Rio de Janeiro: Paz e Terra, 2002.

FURTADO, Celso. Perspectivas da economia brasileira. Rio de Janeiro: Centro Internacional Celso Furtado de Políticas para o Desenvolvimento, [1958] 2012.

LOPES, Herton Castiglioni. Celso Furtado e o progresso técnico. Revista da Sociedade Brasileira de Economia Política. 43 / fevereiro 2016 maio 2016. P. 120-134. Disponível em: http://revistasep.org.br/index.php/ SEP/article/view/161 Acesso em 27/10/2020.

MAUSS, Marcel. Sociologia e Antropologia. São Paulo: Cosac Naify, 2003.

PEREIRA, Luiz Carlos Bresser. Método e paixão em Celso Furtado. In: SOUSA, Cidoval Morais; THEIS, Ivo Marcos; BARBOSA, José Luciano Albino. Celso Furtado: a esperança militante (vol 1). Campina Grande: EDUEPB/A UNIÃO, 2020. P. 85-113.

TENORIO, Fernando; WANDERLEY, Sergio. Celso Furtado: um economista a serviço da gestão pública (1943-1964). Rev. Adm. Pública, Rio de Janeiro, v. 52, n. 3, p. 507-526, June 2018. Available from <http://www.scielo.br/scielo.php?script=sci_arttext\&pid=So034-76122018000300507\&lng=en\&nrm=iso $>$. access on 28 Oct. 2020. https://doi.org/10.1590/o034-7612173859. 